\title{
TRIBOLOGICAL CHARACTERISTIC OF TITANIUM ALLOY SURFACE LAYERS PRODUCED BY DIODE LASER GAS NITRIDING
}

\begin{abstract}
In order to improve the tribological properties of titanium alloy Ti6Al4V composite surface layers Ti/TiN were produced during laser surface gas nitriding by means of a novel high power direct diode laser with unique characteristics of the laser beam and a rectangular beam spot. Microstructure, surface topography and microhardness distribution across the surface layers were analyzed. Ball-on-disk tests were performed to evaluate and compare the wear and friction characteristics of surface layers nitrided at different process parameters, base metal of titanium alloy Ti6Al4V and also the commercially pure titanium. Results showed that under dry sliding condition the commercially pure titanium samples have the highest coefficient of friction about 0.45 , compared to 0.36 of titanium alloy Ti6Al4V and $0.1-0.13$ in a case of the laser gas nitrided surface layers. The volume loss of Ti6Al4V samples under such conditions is twice lower than in a case of pure titanium. On the other hand the composite surface layer characterized by the highest wear resistance showed almost 21 times lower volume loss during the ball-on-disk test, compared to Ti6Al4V samples.

Keywords: titanium alloys, laser gas nitriding, surface layer, wear resistance, ball-on-disk
\end{abstract}

\section{Introduction}

Titanium and titanium alloys are characterized by excellent mechanical properties, high toughness, high strength and relatively low weight [1-4]. Moreover titanium shows great corrosion resistance in many environments, high biocompatibility, and also some titanium alloys show good heat resistance [2,5]. Thus, the combination of these properties and characteristics of titanium alloys have led to successful applications which demand high levels of reliable performance mainly in aerospace, military, automotive, chemical and power plant, petroleum and also in surgery and medicine, as well as in many other major industries [6-9].

At the same time titanium alloys have disadvantages. The most important are a high cost, poor tribological properties such as poor abrasive wear resistance, relatively low hardness and high coefficient of friction [10-13]. The low surface hardness and low wear resistance limit the application of titanium alloys under conditions of friction and contact loads [14-19]. Therefore various methods for improving the surface properties and tribological characteristics of titanium alloys are applied. Tribological properties of titanium alloys may be improved or modified by coatings created on the surface, changing microstructure of surface layers or thermochemical treatments such as nitriding, carburizing, oxidizing or nitrooxidizing, etc. [5,20-23]

The most commonly used methods of surface modification are thermal spraying of coatings, cladding, physical vapour deposition (PVD), chemical vapour deposition (CVD), saltbath nitriding, ion implantation or plasma nitriding [5,24-27].
These methods have been developed and applied for many years.

In the case of thermal spraying and other methods of adhesive layers producing, the crucial parameter, decisive for quality and successful application, is adhesion of the bonding between metallic or ceramic coating and the titanium substrate $[28,29]$. However during plasma spraying an oxide layer may be formed on the titanium metallic surface, which is very harmful and may be the reason of adhesion loss between the coating and metallic substrate. In turn, nitriding of surface layers of titanium alloys is one of most widely used thermochemical treatments in the industry but all the processes of surface nitriding mentioned above have serious disadvantages. For example plasma nitriding requires several hours of processing time [30,31]. Moreover some of the nitriding processes are performed at high temperatures, therefore the bulk of the nitrided sample or a part is exposed to high temperature, so the microstructure and mechanical properties of the bulk material can be also changed and additionally non-uniformity of surface microstructure can occur [32-33]. Additionally, a serious disadvantage of the TiN coatings, reported in the literature, is poor ductility and significant reduction in fatigue wear resistance $[1,5,34]$. In a case of hard coatings composed of titanium nitrides TiN deposited by PVD, CVD and plasma directly on the titanium or titanium alloy substrate, a failure at the interface between the coating and the substrate is very likely $[4,22,35]$. One of the most promising and efficient methods of surface modification of titanium alloys is laser gas nitriding (LGN) [1,4,36-38].

\footnotetext{
* SILESIAN UNIVERSITY OF TECHNOLOGY, FACULTY OF MECHANICAL ENGINEERING, WELDING DEPARTMENT, 18 A KONARSKIEGO STR., 44-100 GLIWICE, POLAND

** BIALYSTOK UNIVERSITY OF TECHNOLOGY, MECHANICAL FACULTY, 45C WIEJSKA STR., 16-351 BIAŁYSTOK, POLAND

\# Corresponding author: aleksander.lisiecki@polsl.pl,
} 
Since the first trials of laser gas nitriding of titanium by Katayama in the eighties of the last century, there have been many studies on the process of laser nitriding of titanium alloys, but the studies were performed under laboratory conditions $[5,15,33]$. Moreover the technology is not applied in the industry yet.

Introduction of the new generation of high power direct diode lasers (HPDDL) to industry allows for further development of the laser surface modification of titanium alloys.

Results of previous investigations on the nitriding of titanium by HPDDL lasers show an advantage of the diode lasers over other types of lasers used for laser gas nitriding $[1,2]$. Therefor the detailed study of tribological characteristic of composite surface layers of titanium alloy Ti6Al4V produced by direct diode laser gas nitriding were undertaken.

\section{Material and experimental procedure}

The most commonly used titanium alloy Ti6Al4V (wt. $\%$, Grade 5) was chosen for surface modification during laser gas nitriding, Table 1 and 2 . Additionally the commercially pure titanium (Grade 2) was chosen as a reference sample (comparative). Laser gas nitriding tests were performed by means of a prototype experimental stand consisted of four-axis computer numerical controlled (CNC) system and a novel high power direct diode laser (HPDDL) ROFIN DL020 with a rectangular beam spot. The rectangular laser beam spot with a width of $1.8 \mathrm{~mm}$ and a length of $6.8 \mathrm{~mm}$ is characterized by multimode, uniform intensity of laser radiation across the beam spot, as show in Figure 1 and given in Table 3 .

The specimens of titanium alloy Ti6Al4V were cut from a hot-rolled rod with a diameter of $50.0 \mathrm{~mm}$. Next the disks were machined by milling and turning to a nominal diameter of $46.0 \mathrm{~mm}$ and a thickness of $3.0 \mathrm{~mm}$. In turn, the specimens of commercially pure titanium were cut from a flat sheet $3.0 \mathrm{~mm}$ thick and then the specimens were machined to a predetermined dimension of test disks. Prior to the laser nitriding the test disks were mechanically ground and rinsed with acetone. Disks were mounted in a rotary drive and set horizontally. The rectangular laser beam was focused on the top surface of disk specimens and set transversely to the travel direction. Pure gaseous nitrogen was fed through a cylindrical nozzle with a diameter of $12 \mathrm{~mm}$. The nitrogen flow rate was kept at $18 \mathrm{l} / \mathrm{min}$. The nitrided single beads had a diameter of $30 \mathrm{~mm}$. The test nitrided surface layers were produced at

TABLE 1

Chemical composition of the commercially pure titanium (Grade 2) and the titanium alloy Ti6Al4V (Grade 5) according to the standard ASTM B 265-99

\begin{tabular}{|c|c|c|c|c|c|c|c|c|}
\hline \multirow{2}{*}{ Material } & \multicolumn{8}{|c|}{ Content of elements, wt $\%$} \\
\hline & $\mathbf{C}$ & $\mathbf{F e}$ & $\mathbf{O}$ & $\mathbf{N}$ & $\mathbf{H}$ & Al & $\mathbf{V}$ & Ti \\
\hline $\begin{array}{l}\text { Commercially pure titanium } \\
\text { (Grade } 2)\end{array}$ & $\begin{array}{c}\max \\
0.1\end{array}$ & $\begin{array}{c}\max \\
0.3\end{array}$ & $\begin{array}{l}\max \\
0.25\end{array}$ & $\begin{array}{l}\max \\
0.03\end{array}$ & $\begin{array}{c}\max \\
0.015\end{array}$ & - & - & Balance \\
\hline $\begin{array}{l}\text { Titanium alloy Ti6A14V (Grade } \\
\text { 5) }\end{array}$ & $\begin{array}{l}\max \\
0.08\end{array}$ & $\begin{array}{l}\max \\
0.25\end{array}$ & $\begin{array}{c}\max \\
0.2\end{array}$ & $\begin{array}{l}\max \\
0.05\end{array}$ & $\begin{array}{c}\max \\
0.015\end{array}$ & $5.5-6.76$ & $3.5-4.5$ & Balance \\
\hline
\end{tabular}

TABLE 2

Physical and mechanical properties of commercially pure titanium, titanium alloy Ti6Al4V and titanium nitride TiN

\begin{tabular}{|c|c|c|c|c|c|c|c|c|}
\hline \multirow{2}{*}{ Material } & \multirow{2}{*}{$\begin{array}{c}\text { Density } \\
\mathrm{g} / \mathrm{cm}^{3}\end{array}$} & \multirow{2}{*}{$\begin{array}{l}\text { Melting point } \\
{ }^{\circ} \mathrm{C}\end{array}$} & \multirow{2}{*}{$\begin{array}{l}\mathbf{R m} \\
\mathrm{MPa}\end{array}$} & \multirow{2}{*}{$\begin{array}{l}\text { Rp0,2 } \\
\text { MPa }\end{array}$} & \multirow{2}{*}{ Elongation A \% } & \multirow{2}{*}{$\begin{array}{c}\text { Contraction } \\
\mathrm{Z} \%\end{array}$} & \multicolumn{2}{|c|}{ Hardness } \\
\hline & & & & & & & HV & HRC \\
\hline $\begin{array}{c}\text { Commercially } \\
\text { pure titanium } \\
\text { (Grade 2) }\end{array}$ & 4.51 & 1665 & $345-450$ & $275-410$ & 20 & 35 & 145 & - \\
\hline $\begin{array}{c}\text { Ti alloy Ti6Al4V } \\
\text { (Grade 5) }\end{array}$ & 4.43 & 1649 & $880-950$ & $820-910$ & $10-18$ & $20-36$ & 349 & 36 \\
\hline TiN & 5.22 & 2930 & - & - & - & - & 2400 & - \\
\hline
\end{tabular}

TABLE 3

Technical data of the continues wave (CW) high power direct diode laser ROFIN DL 020, Fig. 1

\begin{tabular}{|c|c|}
\hline \hline Parameter & Value \\
\hline Wavelength of the laser radiation $(\mathrm{nm})$ & $808-940^{*}( \pm 5)$ \\
\hline Maximum output power of the laser beam $(\mathrm{kW})$ & 2.2 \\
\hline Range of laser power $(\mathrm{kW})$ & $0.1-2.2$ \\
\hline Focal length $(\mathrm{mm})$ & $82 / 32$ \\
\hline Laser beam spot size $(\mathrm{mm})$ & $1.8 \times 6.8$ or $1.8 \times 3.8^{* *}$ \\
\hline Range of laser power intensity $\left(\mathrm{kW} / \mathrm{cm}^{2}\right)$ & $0.8-32.5$ \\
\hline
\end{tabular}

* the dominant wavelength is $808 \mathrm{~nm}$, ** size of the beam spot when an additional lens is applied with a focal length of $32 \mathrm{~mm}$ 
TABLE 4

Parameters of laser gas nitriding of titanium alloy Ti6Al4V disks $3.0 \mathrm{~mm}$ thick by the high power direct diode laser ROFIN DL 020

\begin{tabular}{|c|c|c|c|c|c|c|c|}
\hline $\begin{array}{c}\text { Sample } \\
\text { No. }\end{array}$ & $\begin{array}{c}\text { Scanning speed } \\
(\mathrm{mm} / \mathrm{min}) \\
(\mathrm{mm} / \mathrm{s})\end{array}$ & $\begin{array}{c}\text { Output laser } \\
\text { power }(\mathbf{W})\end{array}$ & $\begin{array}{c}\text { Heat input }(\mathrm{J} / \\
\mathrm{mm})\end{array}$ & $\begin{array}{c}\text { Power* density } \\
\left(\mathrm{W} / \mathbf{c m}^{2}\right)\end{array}$ & $\begin{array}{c}\text { Time of } \\
\text { laser beam } \\
\text { interaction ( } \mathrm{s})\end{array}$ & $\begin{array}{c}\text { Thickness of } \\
\text { TiN layer }(\mathbf{m m})\end{array}$ & Remarks \\
\hline $\mathrm{S} 1$ & $200(3.33)$ & 1000 & 300 & $0.8 \cdot 10^{4}$ & 0.54 & $0.04 \pm 0.001$ & NC, US, HR \\
\hline $\mathrm{S} 2$ & $200(3.33)$ & 800 & 240 & $0.65 \cdot 10^{4}$ & 0.54 & $1.08 \pm 0.037$ & NC, US, HR \\
\hline S3 & $200(3.33)$ & 600 & 180 & $0.49 \cdot 10^{4}$ & 0.54 & $0.98 \pm 0.028$ & NC, HR, UW \\
\hline S4 & $200(3.33)$ & 400 & 120 & $0.32 \cdot 10^{4}$ & 0.54 & $0.90 \pm 0.003$ & $\mathrm{NC}, \mathrm{SF}$ \\
\hline
\end{tabular}

Remarks: laser beam spot size $1.8 \times 6.8 \mathrm{~mm}$, focal length $82.0 \mathrm{~mm}$, diameter of a cylindrical nozzle $12.0 \mathrm{~mm}$, nitrogen gas flow rate 18.0 1/min; NC - no crack, US - uneven surface, HR high roughness of the bead face, UW - uneven width of the bead, SF - smooth surface of the bead face; * in laser physics, the power density of laser beam is defined as a beam intensity

constant scanning sped of $200 \mathrm{~mm} / \mathrm{min}$ and different laser output power from 400 to $1000 \mathrm{~W}$, thus different heat input. Additionally the time of laser beam interaction on the treated surface of titanium alloy was calculated for the beam spot width of $1.8 \mathrm{~mm}$ and scanning speed $200 \mathrm{~mm} / \mathrm{min}$. Previous investigations of the HPDDL nitriding of titanium alloys revealed that the time of integration is an important factor that influences significantly on the process of nitriding even at constant heat input [1].

The test surface layers produced during laser gas nitriding of the titanium alloy Ti6Al4V were examined by visual testing, surface topography analysis and tribological analysis. The surface topography was measured and analyzed by an optical, non-contact Profilograph Micro Prof 100 FRT.

After visual examinations and surface topography analysis some of the samples were sectioned and polished by $180,400,600,1200,1500$ grit $\mathrm{SiC}$ abrasive papers and $0.5 \mu \mathrm{m}$ diamond paste. The metallographic samples were etched by Kroll reagent. The microstructure of base metal and surface layers were examined and analyzed by an optical and also by scanning electron microscopy (SEM). The compounds and the phase composition of the nitrided surface layers were examined by X-ray diffraction (XRD). After metallographic analysis Vickers microhardness was measured and determined on the cross-section of surfaced layers.

The tribological characteristic of the titanium alloy substrate Ti6Al4V, commercially pure titanium and the test nitrided surface layers was evaluated by a ball-ondisk tribometer $\mathrm{T}-01 \mathrm{M}$ under room temperature of $23^{\circ} \mathrm{C}$, according to the ASTM G99 standard. The relative humidity was about $55 \% \pm 5 \%$. Steel balls with a diameter of 10.0 $\mathrm{mm}$ were used as the counterface material. The normal load was set as $30 \mathrm{~N}$. The sliding distance was $188.4 \mathrm{~m}$, while the sliding speed was $0.13083 \mathrm{~m} / \mathrm{s}$. The tangential force of friction and displacement value were continuously measured and recorded during tests using a data acquisition system with PC computer. While the coefficient of friction $\mu$ was calculated by dividing the value of tangential force of friction by the value of normal load used:

$$
\mu=\mathrm{T} / \mathrm{F}_{\mathrm{n}}
$$

where :

$\mathrm{F}_{\mathrm{n}}-$ normal load $(30 \mathrm{~N}), \mathrm{T}-$ tangential force of friction

The results are given in Tables 4 and 6 and also in Figures from 3 to 15 .
TABLE 5

Conditions of the ball-on-disk wear test conducted according to ASTM G99 standard

\begin{tabular}{|c|c|}
\hline \hline Parameter & Value \\
\hline No. of revolutions & $2400($ rev. $)$ \\
\hline Rotational speed & $100(\mathrm{RPM})$ \\
\hline The sliding track diameter & $25(\mathrm{~mm})$ \\
\hline Normal load & $30(\mathrm{~N})$ \\
\hline Ambient temperature & $23\left({ }^{\circ} \mathrm{C}\right)$ \\
\hline
\end{tabular}

a)

b)
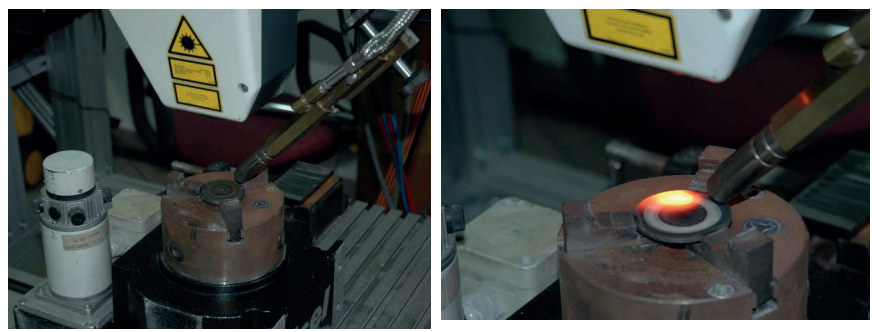

Fig. 1. A view of the experimental setup equipped with the HPDDL Laser ROFIN DL 020 and a rotary drive with the Ti6Al4V disk specimen (a) and a view of the laser gas nitriding process (b)

a)

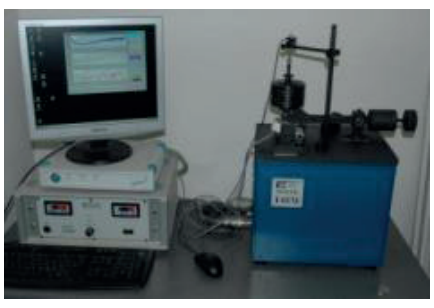

b)

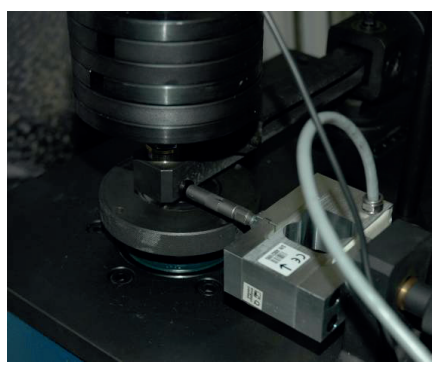

Fig. 2. A view of the tribometer T-01M for ball-on-disk tests according to the ASTM G99 standard

\section{Results and discussion}

\subsection{Morphology of the surface layers}

Visual observation of the laser gas nitrided surface layers revealed a golden shine characteristic for titanium nitride phase, as shown in Fig. 3. In addition, the surface layers produced at the highest output laser power show multicolor tint which is a result of surface oxidation. This is due to the high 
heat input during laser nitriding and thus high temperature of the whole disk surface, even outside the gas shield of nitrogen flow delivered through a cylindrical nozzle having a diameter of $12.0 \mathrm{~mm}$, as shown in Fig. 1b. The surface topography strongly depends on the output laser power, as can be seen in Fig. 3 and 4.

Surface topography of the sample No. 1 produced at maximum output laser power and maximum heat input is not uniform over the entire width of the single bead, Fig. 3a and 4a. The edges are uneven and humped, with deep pitting and hills, while the center of the bead is relatively flat, Fig. 3a and 4a. a)

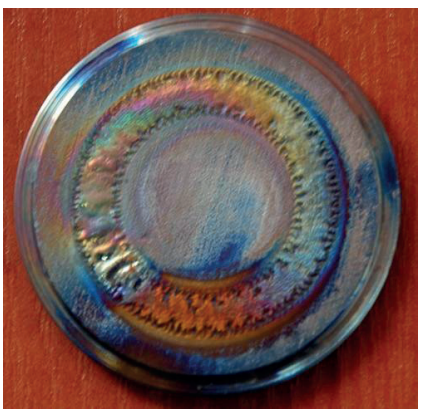

c)

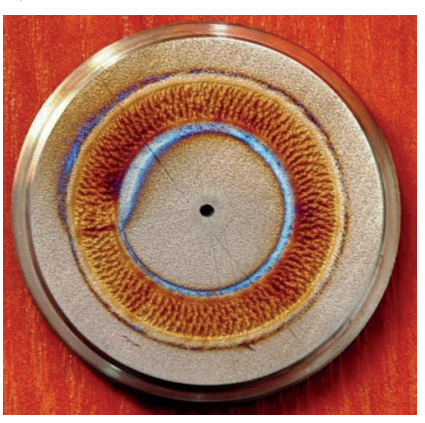

b)

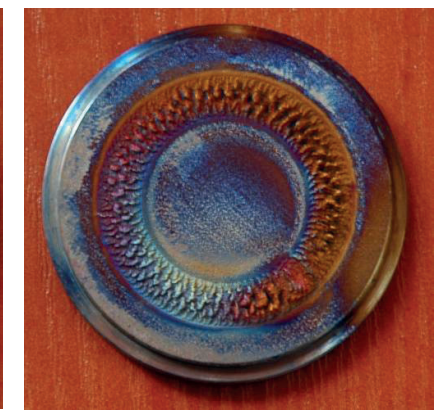

d)

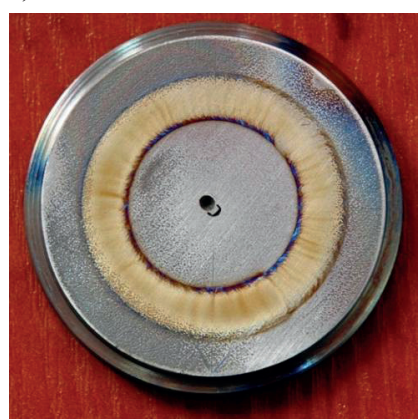

Fig. 3. A view of the test surface layers produced during laser gas nitriding of titanium alloy Ti6Al4V disks $3.0 \mathrm{~mm}$ thick by the high power direct diode laser ROFIN DL 020 (Table 4); a) sample S1 (1.0 $\mathrm{kW}, 0.2 \mathrm{~m} / \mathrm{min}, 300 \mathrm{~J} / \mathrm{mm})$, b) sample S2 $(0.8 \mathrm{~kW}, 0.2 \mathrm{~m} / \mathrm{min}, 240 \mathrm{~J} /$ $\mathrm{mm}), \mathrm{c})$ sample S3 $(0.6 \mathrm{~kW}, 0.2 \mathrm{~m} / \mathrm{min}, 180 \mathrm{~J} / \mathrm{mm})$, d) sample S4 (0.4 $\mathrm{kW}, 0.2 \mathrm{~m} / \mathrm{min}, 120 \mathrm{~J} / \mathrm{mm}$ )

Surface of the sample No. 4 produced at the lowest output laser power and the lowest heat input is very smooth with the lowest roughness ( $\mathrm{Ra} 0.3$ ). In the case of sample No. 2 and 3 produced at intermediate values of output laser power the surface of beads are covered by transverse grooves having a regular form, as shown in Fig. 3b,c. Due to the large irregularities and roughness of the surface layers, samples were slightly grinded before the ball-ondisk wear tests, as shown in Fig. 7. The surface roughness after grinding was approx. Ra 0.3. For comparison, the roughness $\mathrm{Ra}$ of the base metal substrate of titanium alloy Ti6Al4V sheet at the as received conditions was 0.4. Fig. 5 shows the cross-section morphology and XRD spectra of surface layers produced on the titanium alloy Ti6Al4V during laser gas nitriding by means of the HPDDL laser at a constant scanning speed of $200 \mathrm{~mm} / \mathrm{min}$ and at the laser power $1.0 \mathrm{~kW}(300 \mathrm{~J} / \mathrm{mm}), 0.8 \mathrm{~kW}(240 \mathrm{~J} / \mathrm{mm})$ and $0.6 \mathrm{~kW}$ $(180 \mathrm{~J} / \mathrm{mm})$, Table 4. a)
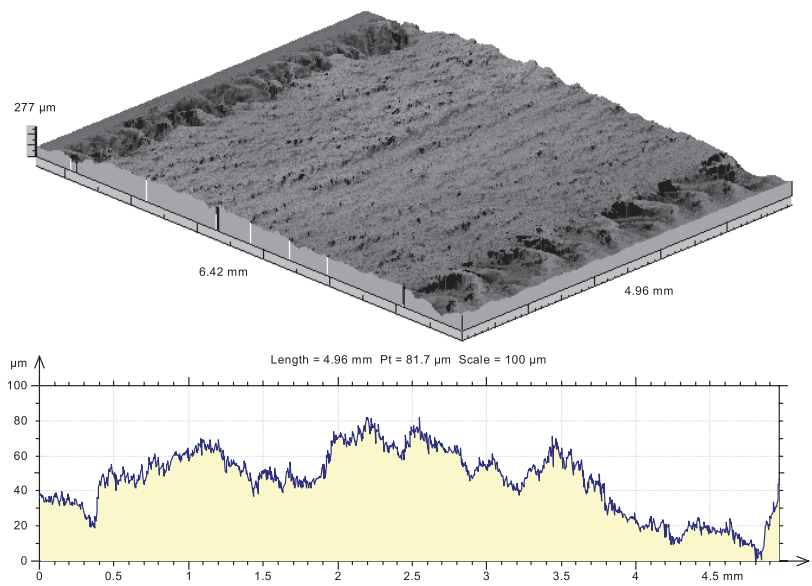

b)

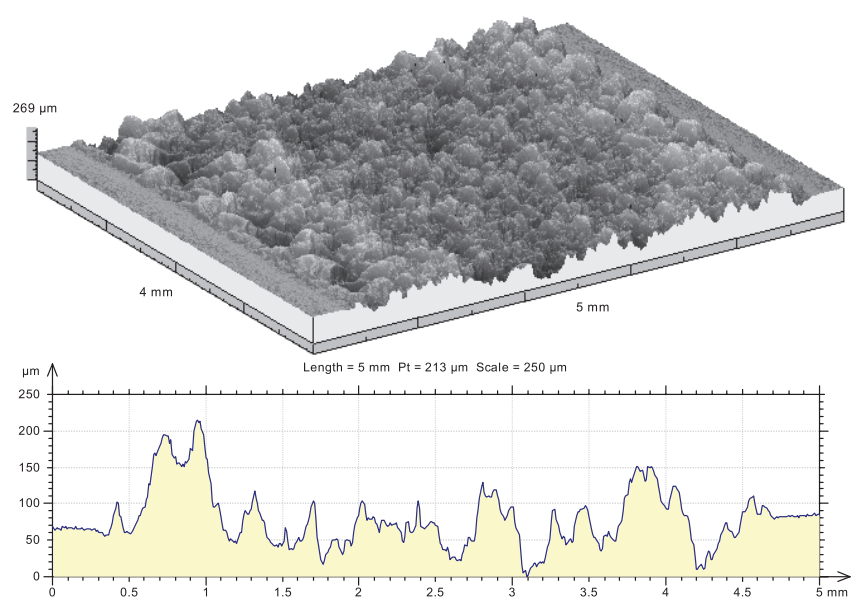

Fig. 4. Three-dimensional surface topography and two-dimensional (cross-sectional) surface profile of the test surface layers; a) S1 produced at $1.0 \mathrm{~kW}$ laser power, $0.2 \mathrm{~m} / \mathrm{min}$ scanning speed, thus heat input of $300 \mathrm{~J} / \mathrm{mm}, \mathrm{b}$ ) S3 produced at $0.6 \mathrm{~kW}$ laser power, $0.2 \mathrm{~m} / \mathrm{min}$ scanning speed, thus heat input of $180 \mathrm{~J} / \mathrm{mm}$ (Table 4)

The regions of XRD analysis for each sample are marked as $\mathrm{A}, \mathrm{B}$ and $\mathrm{C}$ in the Fig. 5. As can be seen, the thickness and composition of the surface layers depend directly on the output laser power. However, regardless of the laser power each surface layer is tightly covered by a thin homogeneous and consistent layer, about 8.0-10.0 $\mu \mathrm{m}$ thick, Fig. 5. Just below the homogeneous layer a zone of dendritic precipitations is placed, Fig. 5. In the near surface region all of the dendrite precipitations are oriented perpendicularly to the top surface, Fig. 5. In a case of the cross-section of the thicker surface layer, produced at maximum laser power of $1.0 \mathrm{~kW}$ (scanning speed $0.2 \mathrm{~m} / \mathrm{min}$, heat input of $300 \mathrm{~J} / \mathrm{mm}$ ) additional transition zone of dendrite precipitations can be observed at a greater depth, Fig. 5a. All surface layers are free of cracks and other imperfections. XRD data obtained from the regions located just below the top surface of the nitrided surface layers (marked as A, B and C in Fig. 5.) showed that the compound layers consist mainly of $\delta$-TiN, Ti $\alpha$ and also $\varepsilon$-Ti2 $\mathrm{N}$ phases in proportion dependent on the output laser power of the HPDDL laser. As can be seen, the structure of the thicker surface layer in the near surface region (A, Fig. 5a), produced at maximum laser power, is composed mainly of the titanium nitrides $\delta$-TiN 
with a smaller share of the $\varepsilon-\mathrm{Ti}_{2} \mathrm{~N}$ nitrides and matrix of Tia Fig. $5 \mathrm{a}$. In this case there are no indications of Ti $\beta$ phase. The single $\mathrm{TiN}_{\mathrm{x}}$ dendrites reach a length up to $300 \mu \mathrm{m}$.

While in the case of the surface layer produced at lower laser power of $0.8 \mathrm{~kW}$ (scanning speed $0.2 \mathrm{~m} / \mathrm{min}$, heat input of $240 \mathrm{~J} / \mathrm{mm}$ ) the XRD pattern obtained from the near surface region (B, Fig. 5b) indicates the $\delta$-TiN and growing share of the $\alpha$-stabilised metal matrix, Fig $5 \mathrm{~b}$. In this case the length of single TiNx dendrites reaches $80-110 \mu \mathrm{m}$, Fig. 5b. The third surface layer presented in the Fig. $5 \mathrm{c}$. was produced at the laser power of $0.6 \mathrm{~kW}$ (scanning speed $0.2 \mathrm{~m} / \mathrm{min}$, heat input of $240 \mathrm{~J} / \mathrm{mm}$ ). The XRD pattern obtained from the near surface region (C, Fig. $5 \mathrm{c}$ ) revealed that the compound layer composition is similar for the previous one. It consists mainly of the $\delta$-TiN phase as well as Ti $\alpha$ matrix but also Ti $\beta$ phase was found. Morphology of the TiN dendrites precipitations in this case is different compared to the surface layers produce at higher laser output power (thus higher heat input). Maximum length of single $\mathrm{TiN}_{\mathrm{x}}$ dendrites doesn't exceed 40-50 mm, Fig. 5c. Differences in the morphologies of surface layers are the result of different heat conditions, thus different melt pool volume and temperature value of the liquid metal. Fig. 6 shows the microhardness distribution on the cross-section of the test surface layers. As can be seen, the microhardness values and its distribution across the surface layers depend clearly on the depth of the layer and phase composition, Fig. 6 .
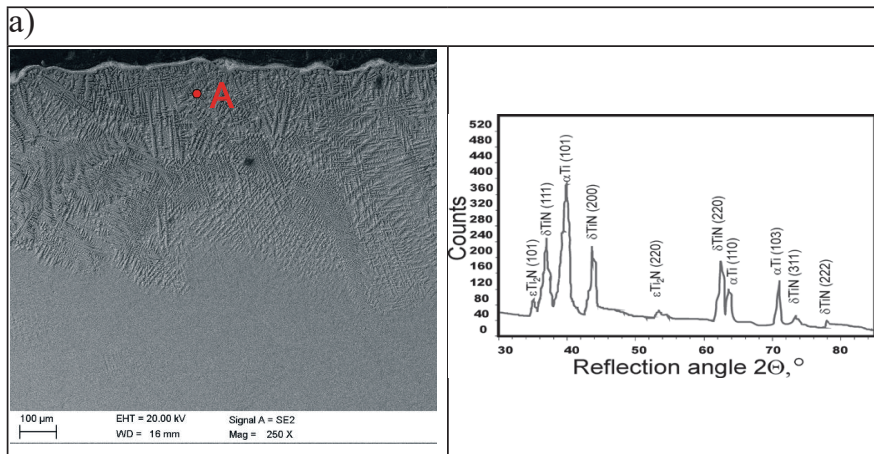

b)
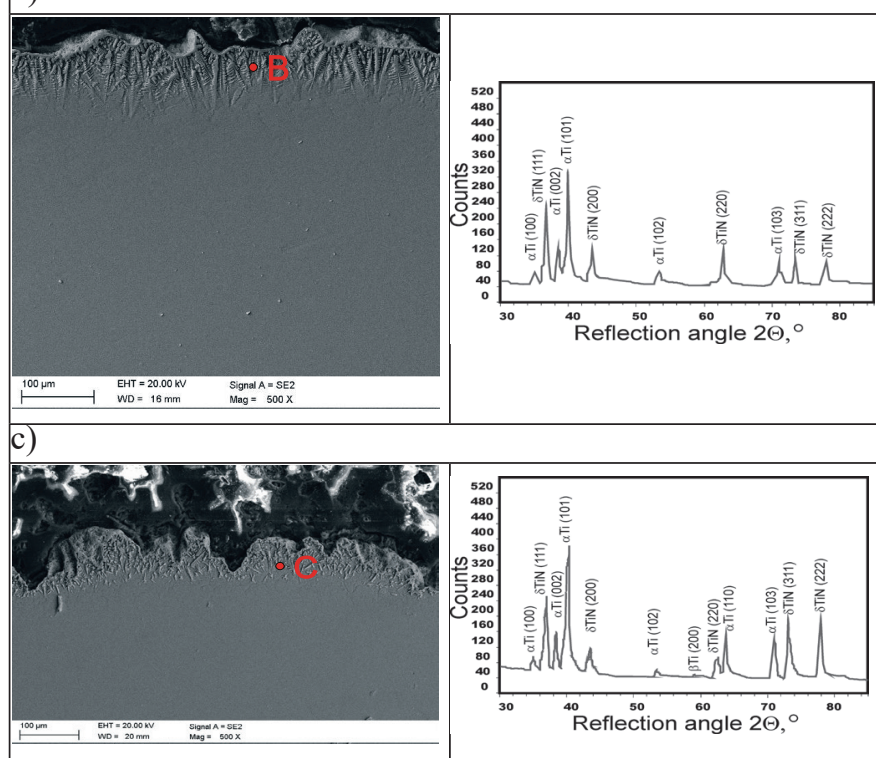

Fig. 5. Scanning electron micrographs SEM of nitrided surface layers and XRD analysis of sample: a) S1, b) S2, c) S3
The maximum value of microhardness about 2400 HV0.2 was measured just below the top surface of sample No. 1 produced at the maximum output laser power of $1.0 \mathrm{~kW}$ and scanning speed $200 \mathrm{~mm} / \mathrm{min}$ (heat input $300 \mathrm{~J} / \mathrm{mm}$ ), Fig. 6 . The microhardness remains at a high level of approx. 1800 HV0.2 to a depth of $0.4-0.5 \mathrm{~mm}$, then decreases gradually to the level of the substrate (base metal), Fig. 6. Such a high hardness is a result of formation of titanium nitride phases and high density of nitrides. The XRD analysis of the sample No. 1 indicates that the high level of microhardness in the near surface region is associated with a large share of nitrides $\delta$-TiN, characterized by the maximum Vickers hardness up to $2400-2500 \mathrm{HV}$ at stoichiometric composition. However, according to the literature data the maximum Vickers hardness of titanium nitride $\delta$-TiN at stoichiometric composition is in the range $1800-2100 \mathrm{HV}$, in the case of $\delta$-TiN layers deposited on metallic substrate the Vickers microhardness may reach $2500 \mathrm{HV}$, as reported by Yu-Chi Lin et al. [4]. The maximum value of microhardness in a case of the sample No. 2 produced at the output laser power of $0.8 \mathrm{~kW}$ (heat input $240 \mathrm{~J} / \mathrm{mm}$ ) is about 1800 HV0.2 just below the top surface, Fig. 6. While in the case of sample No. 3 produced at lower output laser power and lower heat input $(0.6 \mathrm{~kW}, 180 \mathrm{~J} / \mathrm{mm})$ the maximum microhardness does not exceed 1400-1450 HV0.2. This is obviously related to the form and composition (morphology) of the surface layer, as shown in the Fig. $5 \mathrm{c}$. In this case the surface layer is relatively thin (maximum thickness about 100$120 \mu \mathrm{m})$ and the share of hard $\delta$-TiN phase is significantly lower compared to the surface layers produced at higher output laser power, Fig. 5a.

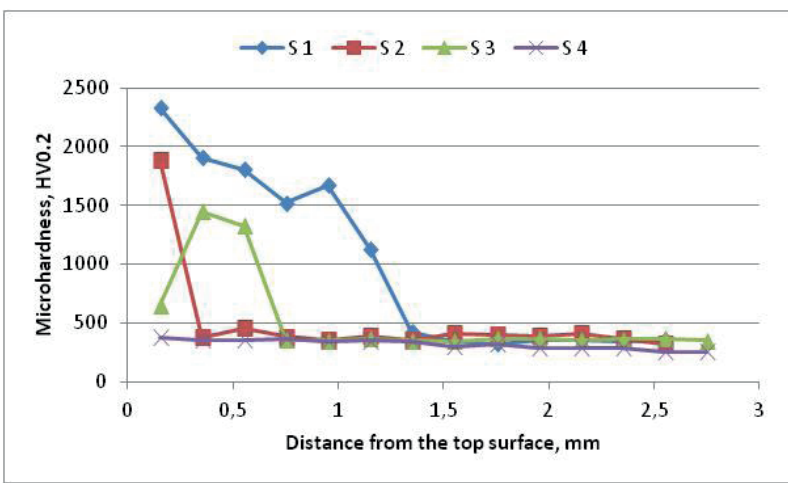

Fig. 6. Microhardness distribution on the cross-section of surface layers after laser gas nitriding of titanium alloy Ti6Al4V specimen $3.0 \mathrm{~mm}$ thick by HPDDL laser (Table 4)

\subsection{Tribological characteristic}

The ball-on-disk wear tests were conducted on the reference sample of commercially pure titanium Grade 2, untreated titanium alloy Ti6Al4V and on four types of the nitrided surface layers produced at different laser power thus different heat input, as shown in Table 4.

As expected, the pure titanium and also the titanium alloy Ti6A14V showed very poor wear resistance in such conditions, as evidenced by the deep and wide wear track on the sample surface. Fig. 7a,b shows the typical morphology of the worn surfaces of the pure titanium, the titanium alloy Ti6Al4V 
substrate and the laser gas nitrided surface layers. While Figs. 8-10 show the cross-sectional profiles of the wear tracks on the surface of samples after sliding for a distance of $188.4 \mathrm{~m}$ at normal load of $30 \mathrm{~N}$ during ball-on-disk tests. a)

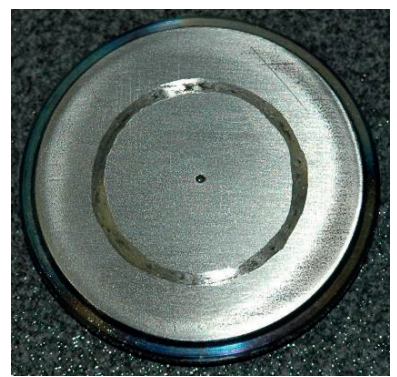

c)

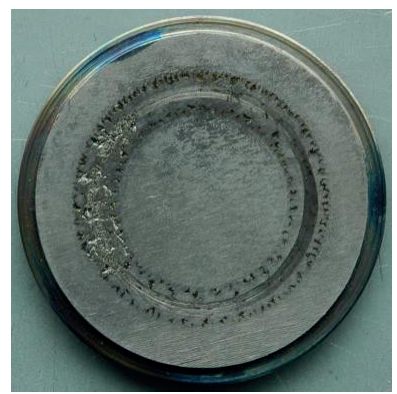

e)

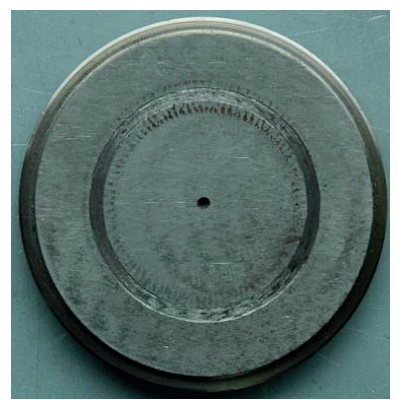

b)

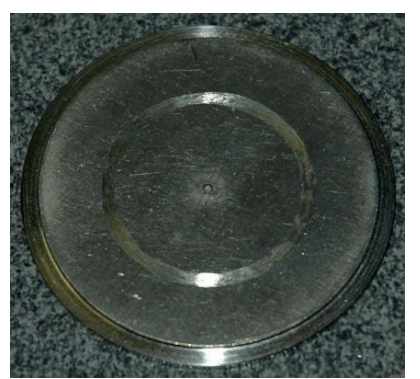

d)

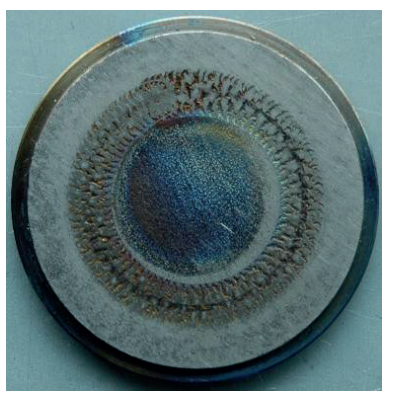

f)

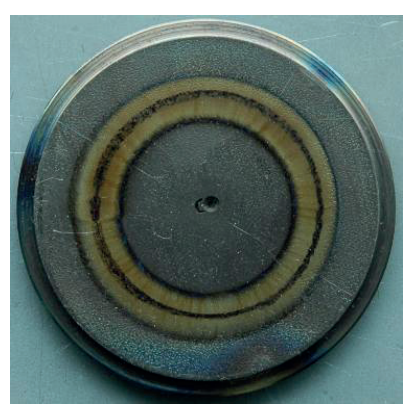

Fig. 7. A view of the disks after ball-on-disk wear tests (Table 4); a) commercially pure titanium, b) Ti6Al4V alloy, c) sample S1, d) sample S2, e) sample S3, f) sample S4

As seen in Fig. 7 and Fig 8, the wear track on the surface of titanium alloy Ti6Al4V has a width of 1.2 to $1.9 \mathrm{~mm}$ and a depth $38 \mu \mathrm{m}$. While the width of the wear track of nitrided surface layer No. 1, produced at the maximum laser power of $1.0 \mathrm{~kW}$ (heat input $300 \mathrm{~J} / \mathrm{mm}$ ), is approx. $1.8 \mathrm{~mm}$ but the depth is considerably smaller and does not exceed 30 micrometers, as shown in Fig. 7, 9. Wear track of nitrided surface layer No. 3 has a smaller depth, which is approx. 13-14 micrometers and the maximum width of the wear track is approx. 1.5, Fig. 7. However, in the case of the nitrided surface layer No. 4, produced at the minimum laser power of $0.4 \mathrm{~kW}$ (heat input $120 \mathrm{~J} / \mathrm{mm}$ ), the wear track is very narrow with a width of
$0.7 \mathrm{~mm}$ and it is just superficial without noticeable trace of cavity, as can be seen in Fig. 7f, 10c. The wear track profiles show that the laser gas nitriding of the titanium alloy Ti6Al4V may significantly improve the tribological properties of the substrate depending on the processing parameters, Table 4.

a)

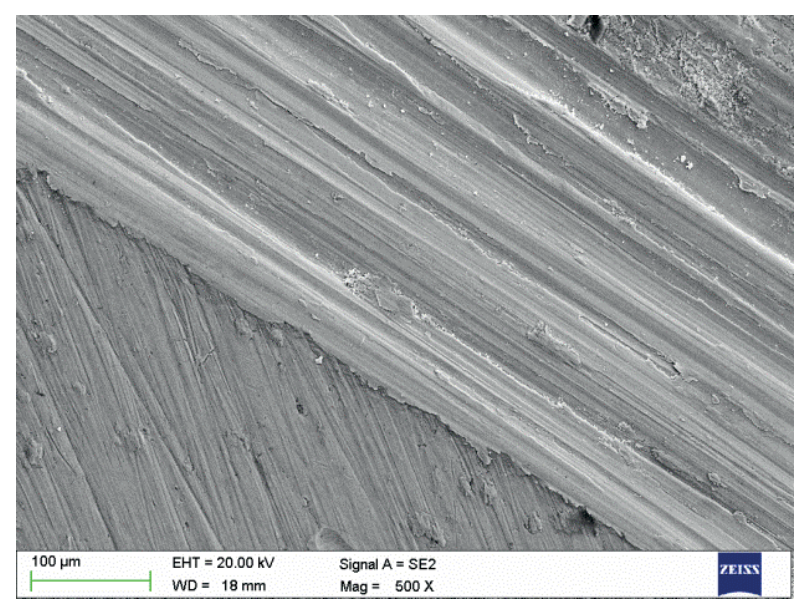

b)

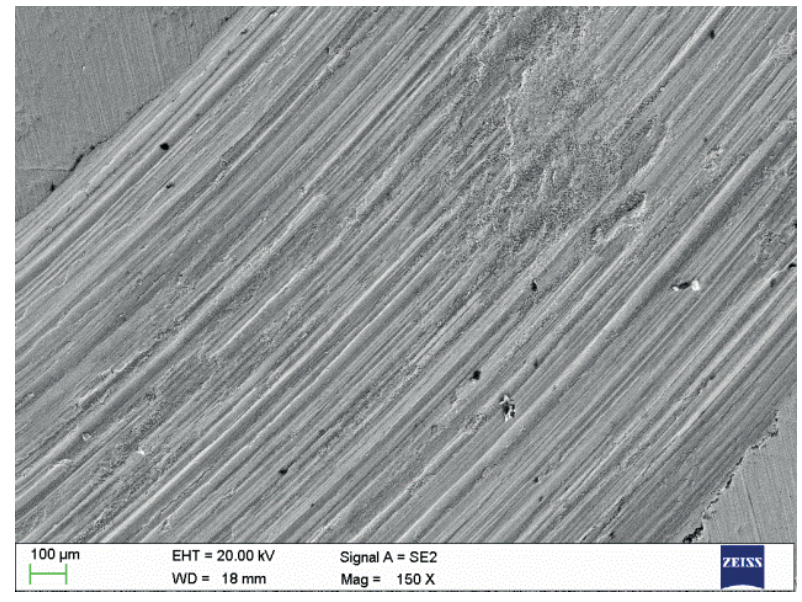

c)

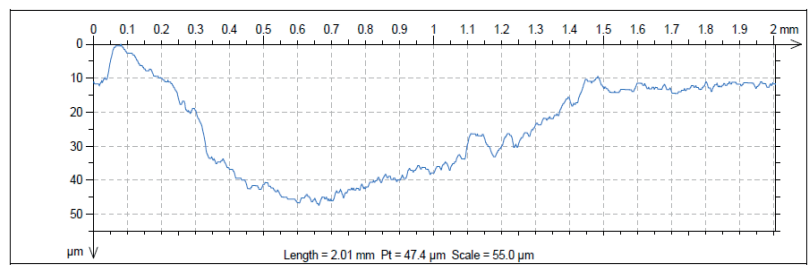

Fig. 8. SEM of the wear tracks on the disks after ball-on-disk tests; a) commercially pure titanium, b) Ti6A14V alloy, and c) cross-sectional profile of the wear track of Ti6Al4V alloy

Variation of the tangential force of friction at the normal load of $30 \mathrm{~N}$ and displacement of the test ball during ball-ondisk test are displayed in Fig. 11 and 12, while the friction coefficients of the disk specimens sliding with a steel ball are displayed in Fig. 13. 
a)

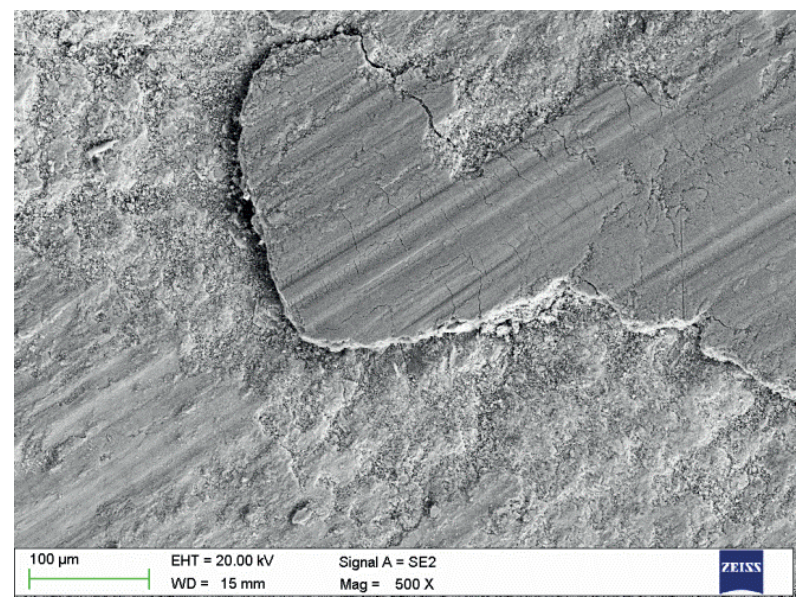

b)

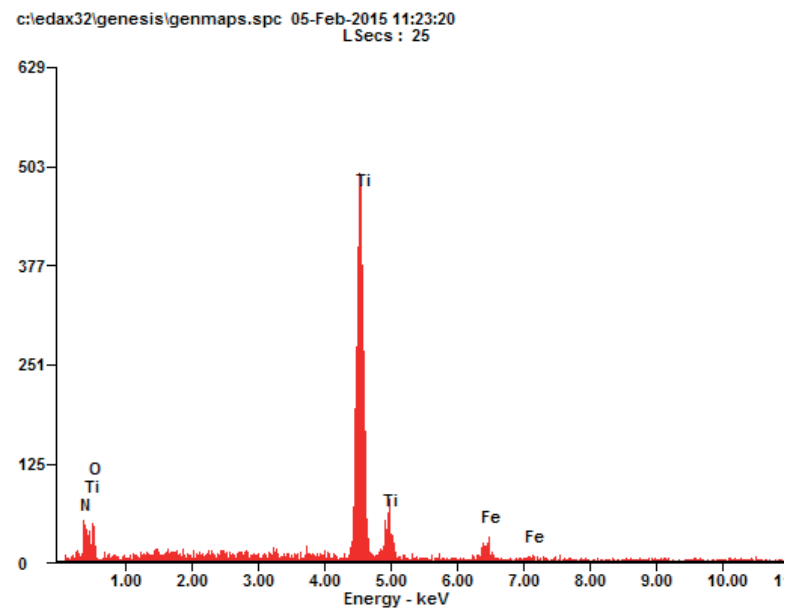

c)

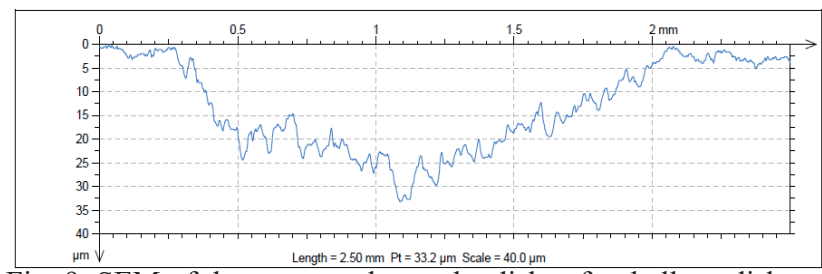

Fig. 9. SEM of the wear tracks on the disks after ball-on-disk test of sample S1 (a), EDS of the debris (b) and cross-sectional profile of the wear track (c)

As can be seen, the coefficient of friction of nitrided surface layers is significantly lower compared to the values measured for the pure titanium and titanium alloy Ti6Al4V. In the case of the nitrided surface layers of titanium alloy Ti6Al4V substrate the friction coefficient values are in the range from 0.1 to 0.18 , Fig. 13 . a)

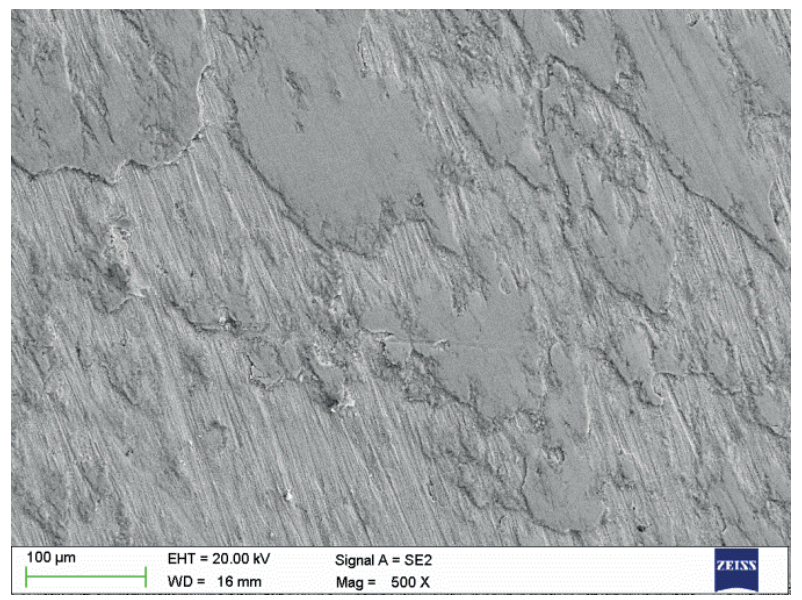

b)

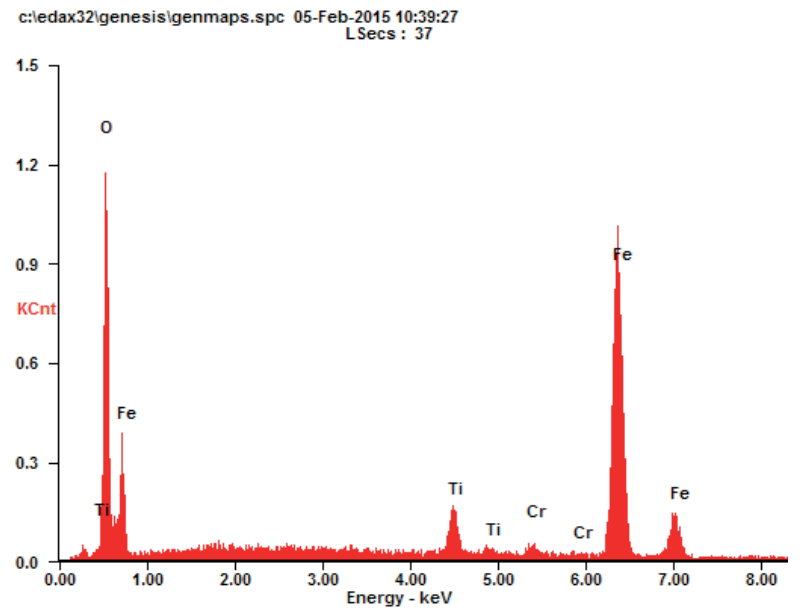

c)

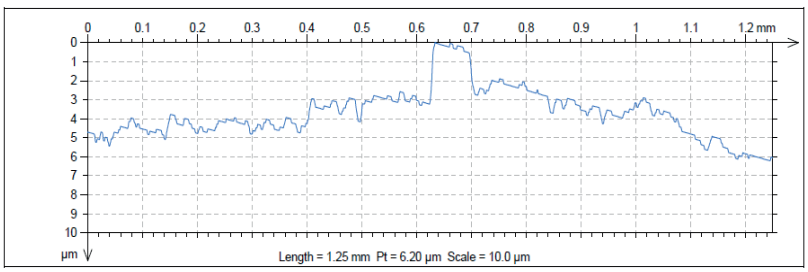

Fig. 10. SEM of the wear tracks on the disks after ball-on-disk test of sample S4 (a) and EDS of the debris (b)

The sample of pure titanium has the highest coefficient of friction of 0.45 , while the sample of titanium alloy Ti6Al4V has a coefficient of friction equal to 0.36 , Fig. 13. The lower coefficient of friction of the test surface layers confirms the increase in wear resistance of the laser gas nitrided surface layers produced on titanium alloy Ti6Al4V substrate.

Figs. 14 and 15 show the weight and volume loss of specimens respectively, after the sliding distance of $188.4 \mathrm{~m}$ at normal load of $30 \mathrm{~N}$. It can be seen that the tribological properties of the titanium alloy Ti6Al4V are significantly higher compared to the commercially pure titanium. The wear resistance of the titanium alloy Ti6A14V is two times higher that commercially pure titanium, as shown in Fig. 15. Laser gas nitriding of the titanium alloy surface further increases the tribological properties and wear resistance. In addition to lowering the coefficient of friction, the wear resistance of the laser gas nitrided surface layer produced on the titanium alloy Ti6Al4V substrate was significantly increased, Fig. 14, 15. 


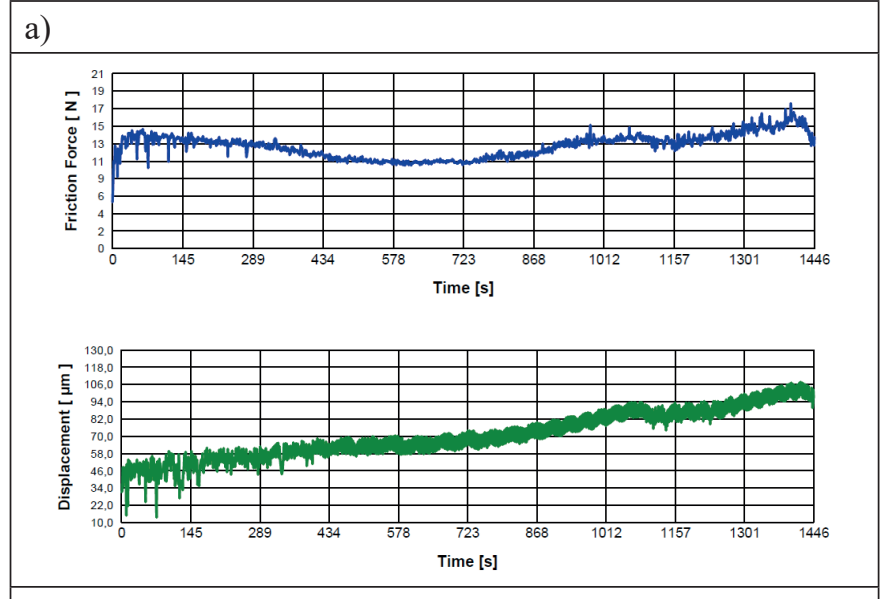

b)
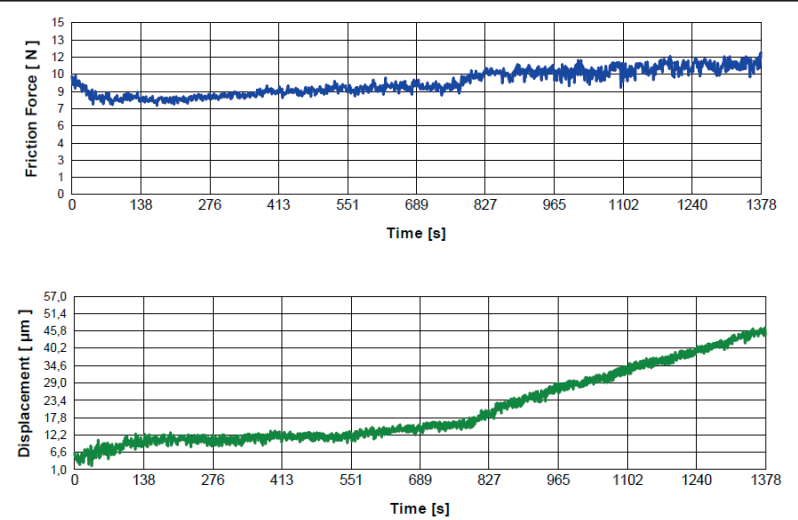

Fig. 11. Variation of the tangential force of friction at the normal load $30 \mathrm{~N}$ and displacement of the test ball during ball-on-disk test of; a) commercially pure titanium, b) titanium alloy Ti6Al4V

The volume loss of sample S4 produced at the lowest laser power is just $0.083 \mathrm{~mm}^{3}$, while the volume loss of the untreated titanium alloy Ti6Al4V is $1.72 \mathrm{~mm}^{3}$. For comparison, the volume loss of the pure titanium is exactly two times greater and equal to $3.44 \mathrm{~mm}^{3}$, as shown in Fig. 14, 15. Fig. 15 , shows also that the volume loss of the steel ball after pure titanium and titanium alloy tests is twice higher compared to the volume loss of the steel ball after tests of nitrided surface layers, as can be seen in Fig. 15. So it is evident that the wear mechanisms of untreated specimens and the nitrided surface layers are different.

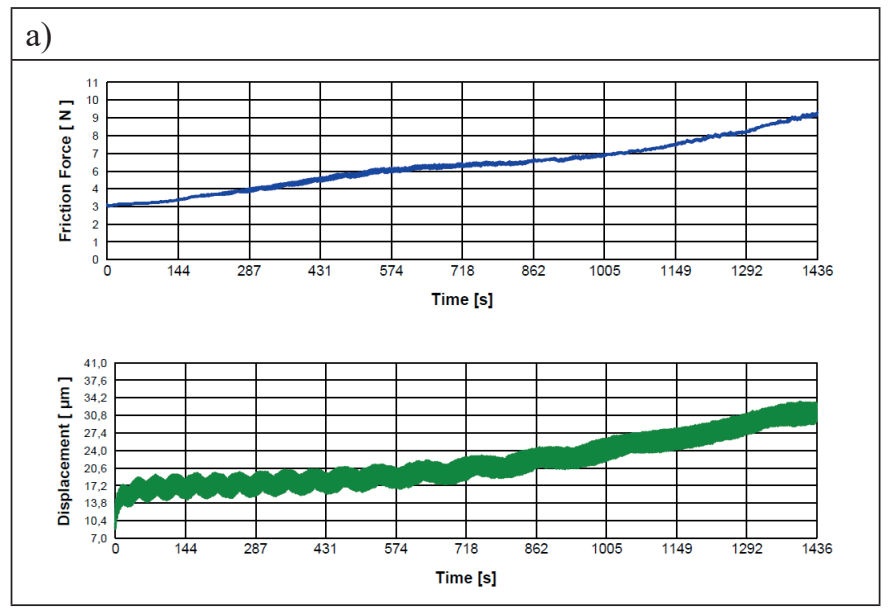

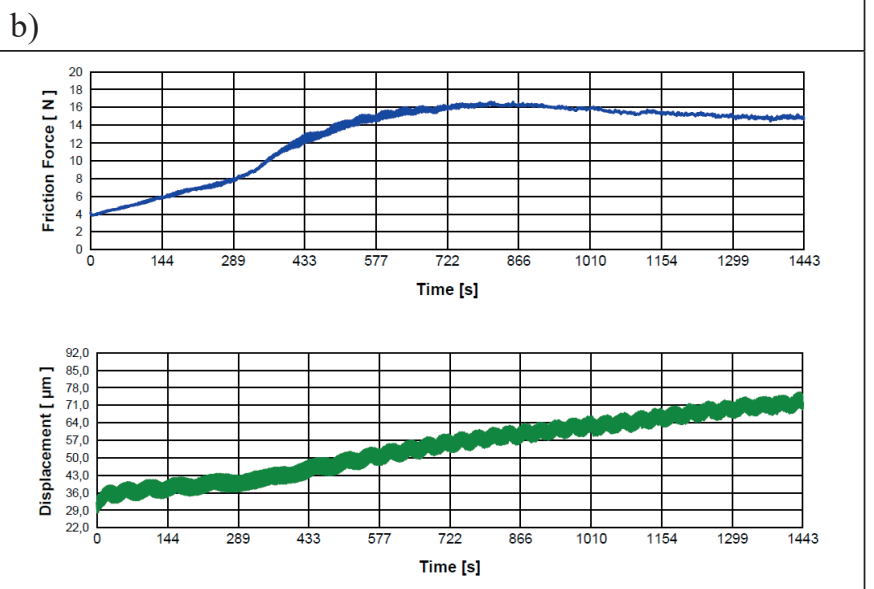

Fig. 12. Variation of the tangential force of friction at the normal load $30 \mathrm{~N}$ and displacement of the test ball during ball-on-disk test of nitrided surface layers; a) S2, b) S4

The inspection and analysis of the wear tracks of pure titanium, titanium alloy and the nitrided surface layers showed that the wear mechanism is combined adhesion and abrasion. In a case of the pure titanium sample the wear track appearance indicates that the dominant mechanism of wear is abrasion. Besides deep plowing groves on the wear track, which are characteristic for severe abrasive wear, there are huge craters across the wear track and plastically deformed regions, as shown in Fig. 8a. Edges of the wear track are plastically deformed. According to the adhesive theory, the adhesive junction between two metallic materials under sliding conditions usually breaks in the softer material. The hardness of the steel ball counterbody (60-62 HRC) is much higher compared to the pure titanium (150-170 HV), therefore the substrate of pure titanium was gradually deformed and torn by the steel ball during the wear tests. It can be seen that in a case of the titanium alloy Ti6Al4V, characterized by higher hardness about 330-350 HV, the traces of adhesive wear are smaller compared to the pure Ti sample. In this case the craters on wear track are smaller and shallower, so the proportions of adhesive and abrasive wear are changed. Further decline in the share of adhesive wear was observed on the wear track of the nitrided surface layer S1, produced at the maximum laser power and characterized by the highest microhardness up to $2400 \mathrm{HV} 0.2$, Fig. 6. In this case the surface wear occurred mainly by the abrasion, as evidenced by the shallow plowing grooves occupying most of the wear track area. Additionally very high areas of steel debris pressed into the wear track of the sample S1 were found. The EDS showed high amount of $\mathrm{Fe}$ and $\mathrm{Cr}$ in the analyzed debris, as shown in Fig. $9 \mathrm{~b}$ and $10 \mathrm{~b}$. In turn the wear track on the surface layer S4 produced at the lowest laser power with the highest wear resistance is quite different. The wear track is just superficial, as can be seen in Fig. $7 \mathrm{f}$ and 10. There are no signs of abrasive wear as can be seen in Fig. 10a. Additionally the cross-sectional profile of the wear track presented in Fig. 10c is convex because of the steel debris adhered on the surface. So the surface layer S4 exhibits very high wear resistance. 
TABLE 6

Results of the ball-on-disk wear test of commercially pure titanium, titanium alloy Ti6Al4V and the test nitrided surface layers (Table 4)

\begin{tabular}{|c|c|c|c|c|c|c|}
\hline \hline Sample No. & $\begin{array}{c}\text { Disk weight loss, } \\
\mathbf{m g}\end{array}$ & $\begin{array}{c}\text { Disk volume loss, } \\
\mathbf{m m}^{\mathbf{3}}\end{array}$ & $\begin{array}{c}\text { Ball weight loss, } \\
\mathbf{m g}\end{array}$ & $\begin{array}{c}\text { Ball volume loss, } \\
\mathbf{m m}^{\mathbf{3}}\end{array}$ & $\begin{array}{c}\text { Coefficient of } \\
\text { friction }\end{array}$ & Remarks \\
\hline Grade 2 & 15.55 & 3.44 & 0.277 & 0.035 & 0.45 & average value \\
\hline Grade 5 & 7.65 & 1.72 & 0.16 & 0.020 & 0.36 & average value \\
\hline S 1 & 6.0 & 1.24 & 0.58 & 0.073 & 0.16 & initial value \\
\hline S 2 & 4.12 & 0.85 & 0.56 & 0.071 & 0.10 & initial value \\
\hline S 3 & 3.8 & 0.78 & 0.41 & 0.052 & 0.18 & initial value \\
\hline S 4 & 0.4 & 0.083 & 0.39 & 0.049 & 0.13 & initial value \\
\hline
\end{tabular}

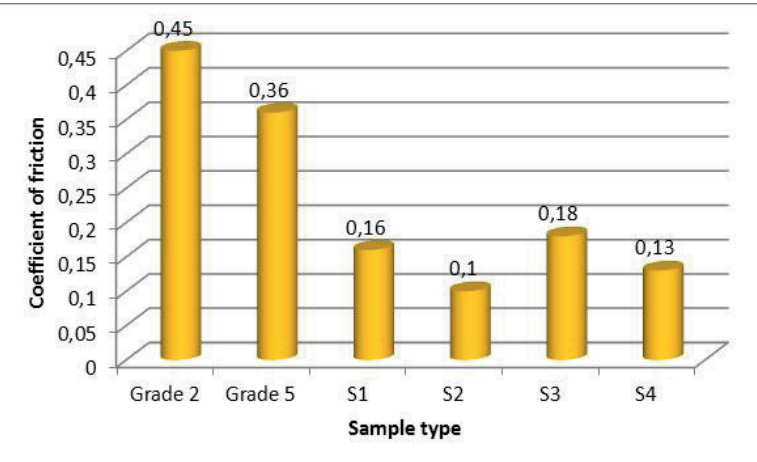

Fig. 13. Comparison of the coefficient of friction of the disk specimens sliding with a steel ball during ball-on-disk wear tests

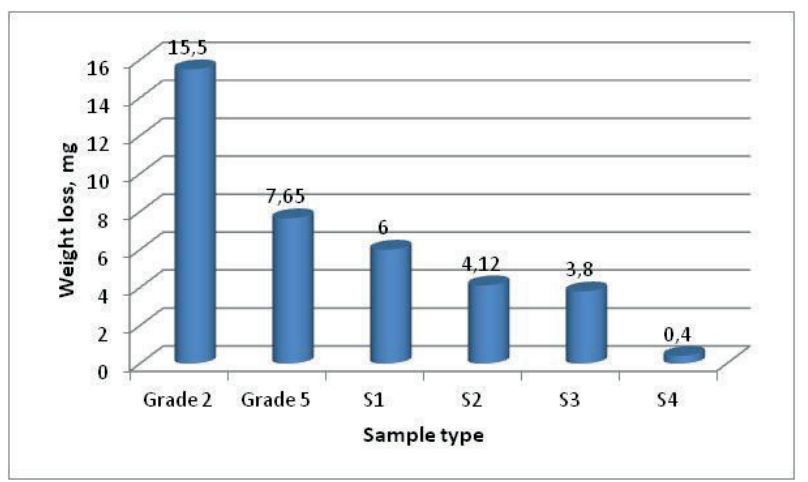

Fig. 14. Weight loss of the disk specimens of commercially pure titanium, titanium alloy and the nitrided surface layers after sliding for a distance of $188.4 \mathrm{~m}$ at normal load of $30 \mathrm{~N}$

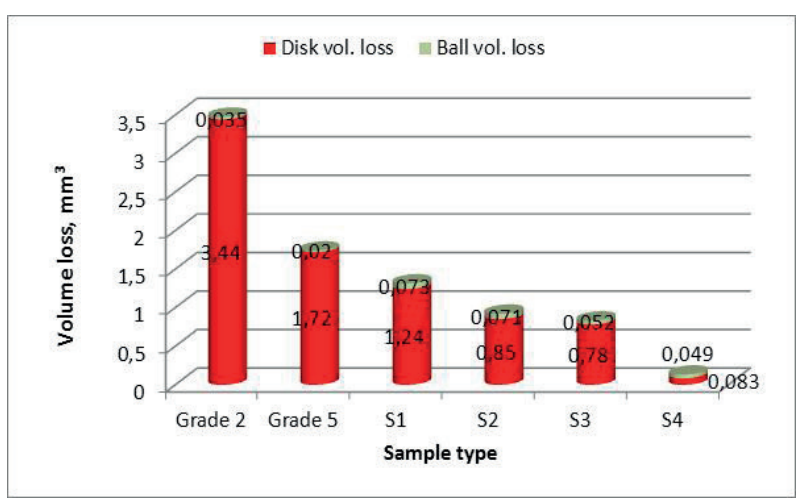

Fig. 15. Volume loss of the counterbody steel ball and the disk specimens of commercially pure titanium, titanium alloy and the nitrided surface layers and after sliding for a distance of $188.4 \mathrm{~m}$ at normal load of $30 \mathrm{~N}$

\section{Conclusions}

This study has shown that the laser gas nitriding of titanium alloy Ti6A14V by the HPDDL laser leads to a significant increase in wear and friction characteristic. Surface layers produced during HPDDL nitriding are cracks free. The tribological characteristics of the nitrided surface layers are related to the processing parameters and thus to the surface topography, morphology and phase composition. Surprisingly the wear resistance of nitrided surface layers during ballon-disk test is not directly correlated to microhardness. The highest wear resistance showed the test surface layer produced at the minimum laser power (thus minimum heat input) and characterized by the lowest Vickers microhardness. The mechanism of wear is combined adhesion and abrasion.

\section{REFERENCES}

[1] A. Lisiecki, Titanium Matrix Composite Ti/TiN Produced by Diode Laser Gas Nitriding, Metals 5(1), 54-69 (2015), doi:10.3390/met5010054.

[2] A. Lisiecki, Mechanism of Laser Surface Modification of the Ti-6Al-4V Alloy in nitrogen atmosphere using a High Power Diode Laser, Advanced Materials Research 1036, 411-416 (2014), doi:10.4028/www.scientific.net/AMR.1036.411

[3] M. Mubarak, Influence of plasma nitriding on fretting wear behaviour of Ti-6Al-4V, Trib. Inter. 43, 152-160 (2010).

[4] Y u-Chi Lin et al., The effect of different methods to add nitrogen to titanium alloys on the properties of titanium nitride clad layers, Mater. Des. 54, 222-229 (2014).

[5] S. Katayama, et al., Surface hardening of titanium by laser nitriding. In Proceedings of the ICALEO'83, Los Angeles, CA, USA, pp. 127-134. 14-17 November 1983.

[6] A. Lisiecki, Welding of titanium alloy by Disk laser, Proceedings of SPIE, Laser Technology 2012: Application of Lasers, 8703 (2013), DOI:10.1117/12.2013431.

[7] D. Janicki, High Power Diode Laser Cladding of Wear Resistant Metal Matrix Composite Coatings, Sol. St. Phenomena, Mechatronic Systems and Materials V, 199, 587-592 (2013).

[8] L.A. Dobrzanski, M. Bonek. A. Klimpel, A. Lisiecki, Surfacelayer's structure of X40CrMoV5-1 steel remelted and/or WC alloyed with HPDL laser, Advanced Materials Processing II, Materials Science Forum, 437-4, 69-72 (2003).

[9] G. Moskal, A. Grabowski, A. Lisiecki, Laser remelting of silicide coatings on Mo and TZM alloy, Sol. St. Phenomena 226, 121-126 (2015). DOI:10.4028/www.scientific.net/ 


\section{SSP.226.121}

[10] M. Bonek, L.A. Dobrzański, Characterization performance of laser melted commercial tool steels, Mat. Sci. Forum 654-656, 1848-1851 (2010).

[11] A. Klimpel, L.A. Dobrzanski, D. Janicki, A. Lisiecki, Abrasion resistance of GMA metal cored wires surfaced deposits, J. Mat. Proc. Tech. 164, 1056-1061 (2005) doi: 10.1016/j. jmatprotec.2005.02.242.

[12] T. Węgrzyn, J. Piwnik, B. Łazarz, D. Hadryś, Main micro-jet cooling gases for steel welding, Arch. Metall. Mater. 58(2), 555-557 (2013).

[13] T. Węgrzyn, J. Mirosławski, A. Silva, D. Pinto, M. Miro s, Oxide inclusions in steel welds of car body, Mat. Sci. Forum 6, 585-591 (2010).

[14] A. Kurc-Lisiecka, W. Ozgowicz, W. Ratuszek, J. Kowalska: Analysis of Deformation Texture in AISI 304 Steel Sheets, Sol. St. Phenomena 203-204, 105-110 (2013).

[15] J. Jezierski, K. Janerka, Parameters of a Gas-Solids Jet in Pneumatic Powder Injection into Liquid Alloys with a NonSubmerged Lance, Metalurgija 54(2), 365-367 (2015).

[16] W. Sitek, L.A. Dobrzański, Comparison of hardenability calculation methods of the heat-treatable constructional steels, J. Mat. Proc. Tech. 64(1-3), 117-126 (1995).

[17] T. Węgrzyn, J. Piwnik, D. Hadryś. Oxygen in steel WMD after welding with micro-jet cooling, Arch. Metall. Mater. 58(4), 1067-1070 (2013).

[18] B. Oleksiak, G. Siwiec, A. Blacha-Grzechnik, J. Wieczorek, The obtained of concentrates containing precious metals for pyrometallurgical processing, Metalurgija 53(4), 605-608 (2014).

[19] J. Górka, Analysis of simulated welding thermal cycles S700MC using a thermal imaging camera, Adv. Mat. Res. ISI Proceedings 837, 375-380 (2014).

[20] G. Golański, J. Słania, Effect of different heat treatments on microstructure and mechanical properties of the martensitic GX12CrMoVNbN9-1 cast steel, Arch. Metall. Mater. 58(1), 25-30 (2013).

[21] G. Golański, P. Gawień, J. Słania, Examination of Coil Pipe Butt Joint Made of 7CrMoVTib10 - 10(T24) Steel After Service, Arch. Metall. Mater. 57(2), 1067-1070 (2012).

[22] L. Blacha, J. Mizera, P. Folega, The effects of mass transfer in the liquid phase on the rate of aluminium evaporation from the Ti-6Al-7Nb alloy, Metalurgija 53(1), 51-54 (2014).

[23] T. Węgrzyn, J. Piwnik, Low alloy steel welding with micro-jet cooling, Arch. Metall. Mater. 57(2), 539-543 (2012).

[24] B. Oleksiak, M. Koziol, J. Wieczorek, M. Krupa, P. Folę g a, Strength of briquettes made of cu concentrate and carbonbearing materials, Metalurgija 54(1), 95-97 (2015).

[25] G. Golański, J. Jasak, J. Słania, Microstructure, properties and welding of T24 steel - critical review, Kovove Materialy 52,
99-106 (2014).

[26] R. Burdzik, Ł. Konieczny, Research on structure, propagation and exposure to general vibration in passenger car for different damping parameters, J. of Vibroengineering 15(4), 1680-1688 (2013).

[27] W. Tarasiuk, B. Szczucka-Lasota, J. Piwnik, W. Majewski, Tribological Properties of Super Field Weld with Micro-Jet Process, Adv. Mat. Res. 1036, 452-457 (2014).

[28] D. Janicki, High Power Diode Laser Cladding of Wear Resistant Metal Matrix Composite Coatings, Solid State Phenomena, Volume: Mechatronic Systems and Materials V, 587-594 (2013).

[29] R. Burdzik, Ł. Konieczny, T. Figlus, Activities of Transport Telematics, Book Series: Communications in Computer and Information Science 395, 418-425 (2013).

[30] R. Burdzik, Research on the influence of engine rotational speed to the vibration penetration into the driver via feet - multidimensional analysis, J. of Vibroengineering 15(4), 2114-2123 (2013).

[31] R. Burdzik, Z. Stanik, J. Warczek, Method of assessing the impact of material properties on the propagation of vibrations excited with a single force impulse, Arch. Metall. Mater. 57(2), 409-416 (2012).

[32] J. Bodzenta, A. Kaźmierczak, T. Kruczek, Analysis of thermograms based on FFT algorithm, Journal de Physique IV 129, 201-206 (2005).

[33] A. Grajcar, M. Różański, S. Stano, A. Kowalski, B. Grzegorczyk, Effect of Heat Input on Microstructure and Hardness Distribution of Laser Welded Si-Al TRIP-Type Steel, Adv. in Mat. Sci. and Eng. 2014 (2014),

[34] A. Grajcar, M. Różański, S. Stano, A. Kowalski, Microstructure characterization of laser-welded Nb-microalloyed siliconaluminum TRIP steel, Journal of Materials Engineering and Performance 23(9), 3400-3406 (2014).

[35] M. Kulka, D. Panfil, J. Michalski, P. Wach, The effects of laser surface modification on the microstructure and properties of gas-nitrided 42CrMo4 steel, Optics and Laser Technology 82, 203-219 (2016).

[36] A. Grabowski, et al., Optical and conductive properties of AlSialloy/SiCp composites: application in modeling $\mathrm{CO}_{2}$ laser processing of composites, Optics and Lasers in Engineering 43, 233-246 (2005).

[37] H. Bąkowski, A. Posmyk, J. Krawczyk, Tribological properties of rail steel in straight moderately loaded section of railway trucks. Archives of Metallurgy and Materials. 56 (3) 813-822, (2011).

[38] A. Posmyk, H. Bąkowski, Wear mechanism of cast iron piston ring/aluminum matrix composite cylinder liner. Tribology Transactions, 56 (5), 806-815 (2013). DOI: 10.1080/10402004.2013.798878. 